\title{
CSA Doped Poly(aniline-co-o-toluidine) and Dispersed Zinc Oxide Nanoparticles: a Promising Material for Photovoltaics
}

\author{
Arunachalam Mahudeswaran ${ }^{a}$, Devarajan Manoharan ${ }^{b}, J o s e p h$ Chandrasekaran ${ }^{b}$, \\ Janakiraman Vivekanandan ${ }^{a}$, Pachanoor Subbaian Vijayanand ${ }^{a *}$ \\ ${ }^{a}$ Department of Physical Sciences, Bannari Amman Institute of Technology, 638401, \\ Sathyamangalam, Tamil Nadu, India \\ ${ }^{b}$ Materials Science Laboratory, Department of Physics, Sri Ramakrishna Mission Vidyalaya College of \\ Arts and Science, 641020, Coimbatore, Tamil Nadu, India
}

Received: June 10, 2014; Revised: March 25, 2015

\begin{abstract}
Copolymerization of aniline and o-toluidine is achieved by chemical oxidative polymerization with equal molar ratio of monomers in the presence of hydrochloric acid and ammonium persulphate as an oxidant. The copolymer found to be more soluble in polar solvents such as NMP, DMF and DMSO. FTIR spectroscopy confirms the copolymer chemical structure. UV spectroscopy shows $\pi$ to $\pi^{*}$ transition and excitonic transition of the copolymer film. The copolymer is doped with camphorsulfonic acid (CSA) in $\mathrm{m}$-cresol and then zinc oxide nanoparticles are dispersed into the copolymer and spin coated on to a glass plate. The scanning electron microscope image shows the morphology of the copolymer matrix. X-ray Diffraction shows the characteristic peaks of CSA and zinc oxide. EDAX analysis confirms the presence of CSA and zinc oxide. The dispersion of zinc oxide nanoparticles show quenching property of photoluminescence indicating that the copolymer can be used in the opto-electronics.
\end{abstract}

Keywords: copolymer, camphorsulfonic acid, zinc oxide, photoluminescence, quenching, optoelectronics

\section{Introduction}

Polyaniline (PANI) and its derivatives have been extensively studied in the last decade with improved processing and intrinsic electrical properties. They have received great attention owing to its ease of synthesis, good stability in the presence of oxygen and possessing electrochemical properties of unique conducting mechanism. This polymer can be obtained by electrochemical and chemical oxidative polymerization of aniline in aqueous solutions. Poly (o-toluidine) is a PANI derivative which contains the $-\mathrm{CH}_{3}$ group in the ortho position of the aromatic ring of the aniline monomer. Among the ring-substituted PANI derivatives, Poly (o-toluidine) has been most widely studied one. With regard to polyaniline based copolymers, a pioneering work has been reported about aniline copolymerization with o-toluidine and aminoacetophenone possessing conductivity property of broad range $\mathrm{e}^{1-4}$. The copolymer was found to be soluble in common organic solvents like $\mathrm{CHCl}_{3}$, THF, DMF, NMP and $\mathrm{DMSO}^{5}$. The thermal stability of the copolymer was studied and found to vary irregularly with AN-OT molar ratio ${ }^{6-8}$.

The copolymer shows new morphology with higher thermal stability and better solubility than its homopolymers. Potentiodynamic polarization and electrochemical impedance spectroscopy have been employed to study the corrosion inhibition effects of this copolymer on carbon steel ${ }^{9}$. Recently it has been reported that the metal composite of poly (aniline-co-o-toluidine)- $\mathrm{BaFe}_{12} \mathrm{O}_{19}$ composite exhibited a ferro

*e-mail: vijayps6@yahoo.co.in magnetic behavior ${ }^{10}$. Juliet et al reported the characterization of copolymerization of aniline-co-o/m-toluidine and $\mathrm{V}_{2} \mathrm{O}_{5}$ nanocomposites ${ }^{11}$. Optical band gap of PANI-co-POT thin film are found to be lower than that of POT films and shows a rectifying behavior ${ }^{12}$ and a spin coated thin film of polyaniline doped with camphorsulfonic acid (CSA) has been found to possess novel microstructure surface for $\mathrm{NH}_{3}$ detection at room temperature with better response ${ }^{13}$. Polyaniline has been used as an effective candidate as hole transporting layer in organic solar cells instead of PEDOT:PSS ${ }^{[14,15]}$. Polyaniline with amorphous silicon in heterojunction solar cells has been reported and found to have higher open circuit voltages in the solar cells ${ }^{16}$. Among metal oxide nanoparticles, zinc oxide nanoparticles possess their own importance due to their vast area of applications as gas sensor, chemical sensor, optical, electrical devices and solar cells $\mathrm{s}^{17-21}$. $\mathrm{ZnO}$ nanoparticles are becoming promising semiconductor oxides when applied as an electron transport material ${ }^{22}$. Zinc oxide nanoparticles has been synthesized and used in dye sensitized solar cells ${ }^{23}$. Addition of $\mathrm{ZnO}$ nanoparticles into the copolymer chain will improve their compatibility and increases the thermal stability of the copolymer ${ }^{24}$. Polyaniline- $\mathrm{ZnO}$ nanocomposite thin film has been fabricated on glass substrates by vacuum deposition technique ${ }^{25}$. It has been reported that polymers doped with organic acids lead to possess high conductivity because organic solvents such as $m$-cresol and other substituted phenols act as secondary dopants ${ }^{26-33}$. 
The aim of the present research work is to synthesize, characterize and study the electronic properties of poly(aniline-co-o-toluidine) copolymer doped with CSA and dispersion of $\mathrm{ZnO}$ nanoparticles. The synthesized copolymer composites are spin coated to form a thin film using spin coating technique. The film is then subjected to various characterization techniques such as UV-Vis, FTIR, PL, XRD, SEM and EDAX.

\section{Material and Methods}

The chemicals used for the synthesis are of AR grade. Aniline monomer and ammonium persulphate (APS) were purchased from Merck and o-toluidine from Lobachime. Camphorsulfonic acid and zinc oxide nanoparticles were purchased from Sigma Aldrich. 0.1 $\mathrm{M}$ aniline $(0.5 \mathrm{ml}$ in $50 \mathrm{ml}$ of $1 \mathrm{M} \mathrm{HCl}$ solution) and $0.1 \mathrm{M}$ o-toluidine $(0.5 \mathrm{ml}$ in $50 \mathrm{ml}$ of $1 \mathrm{M} \mathrm{HCl}$ solution) monomers were added in a $250 \mathrm{ml}$ round bottom flask. $0.2 \mathrm{M}$ ammonium persulfate solution (4.56 gm of APS dissolved in $100 \mathrm{ml}$ of $1 \mathrm{M} \mathrm{HCl}$ solution in separation funnel and it was added drop wise to the monomer mixture. As soon as the oxidant was added, the polymerization reaction began in the $1 \mathrm{M}$ of hydrochloric acid medium. The reaction mixture was allowed to stir continuously for four hours. The temperature of the reaction mixture was maintained between $0^{\circ} \mathrm{C}$ to $5^{\circ} \mathrm{C}$. The obtained copolymer was washed and filtered. A dark green precipitate is obtained and dried in vacuum at $60^{\circ} \mathrm{C}$. The obtained green colored emeraldine salt was an $\mathrm{HCl}$ doped polymer. The copolymer was undoped by mixing with $50 \%$ of aqueous ammonia solution $(50 \mathrm{ml}$ of ammonia added in $50 \mathrm{ml}$ of distilled water) and allowed to stir continuously for four hours. A dark bluish color was obtained and dried. The emeraldine base of the copolymer was doped CSA with a ratio of 1:5 in $1 \mathrm{ml}$ of $\mathrm{m}$-cresol in $5 \mathrm{ml}$ vial which acts as a medium and secondary dopant. The solution was stirred for 5 days to get homogeneous solution. Finally the resultant solution was spin coated at $750 \mathrm{rpm}$ for $20 \mathrm{secs}$. Zinc oxide nanopowder (2 mg) was dispersed into the CSA doped copolymer and then it was spin coated on a glass plate to form a thin film. The copolymer, CSA and $\mathrm{ZnO}$ in the composite are in the ratio of 1:5:1.

\subsection{Characterization}

The synthesized copolymer was characterized with FT-IR analysis which was recorded using Perkin Elmer FTIR Spectrometer as with $\mathrm{KBr}$ pellets. The samples were coated into thin film by using Programmable spin coater SCU 2008C. The thin film was characterized by UV-Vis spectroscopy using JASCO-V570 spectrophotometer. X-ray diffraction patterns were taken using Philips model TW 1710 diffractometer with $\mathrm{Cu} \mathrm{K} \alpha$ radiation of 1.5417 angstrom. The SEM and EDAX were taken using Philips XL 30. Photoluminescence spectra were recorded using FT 600 spectroflurometer.

\section{Results and Discussion}

\subsection{FTIR analysis}

Figure 1 represents the FT-IR spectrum of the synthesized copolymer. The characteristic peak about $3350 \mathrm{~cm}^{-1}$ corresponds to the $\mathrm{N}-\mathrm{H}$ stretching of the primary amine and confirms the amino group. The peak at $2920 \mathrm{~cm}^{-1}$ attributes to the $\mathrm{C}-\mathrm{H}$ stretching vibration of methyl group. The absorption peak at $1590 \mathrm{~cm}^{-1}$ is assigned to the quinoid ring stretching. The peak observed at $1494.20 \mathrm{~cm}^{-1}$ corresponds to the presence of $\mathrm{C}=\mathrm{C}$ stretching vibration in benzenoid ring. The sharp peak at $809.39 \mathrm{~cm}^{-1}$ attributes the para-coupled phenyl ring in the copolymer. The absorption band around $1145 \mathrm{~cm}^{-1}$ confirms the charge delocalization. The peak at $1297.78 \mathrm{~cm}^{-1}$ corresponds to the $\mathrm{C}-\mathrm{N}$ stretching vibrations of the aromatic primary amine ${ }^{5}$.

\subsection{UV-Visible analysis}

The UV-Vis spectrum of the copolymer from NMP is shown in the Figure 2. There are two absorption peaks observed in the spectrum at $337 \mathrm{~nm}$ and $603 \mathrm{~nm}$ respectively. The peak at $337 \mathrm{~nm}$ corresponds to the $\pi-\pi^{*}$ transition. The peak at $603 \mathrm{~nm}$ corresponds to excitonic transition between highest occupied molecular orbital of the benzenoid ring and lowest unoccupied molecular orbital in quinoid ring or $\mathrm{n}-\pi^{*}$ transition of the copolymer ${ }^{34}$.

\subsection{XRD analysis}

Figure 3 a shows the X-ray diffraction of the copolymer. It shows the broad amorphous diffraction peak due to the presence of benzoid and quinoid rings of copolymer. Figures 3b, c show X-ray diffraction of the pure CSA and copolymer doped with CSA thin film respectively. Since the

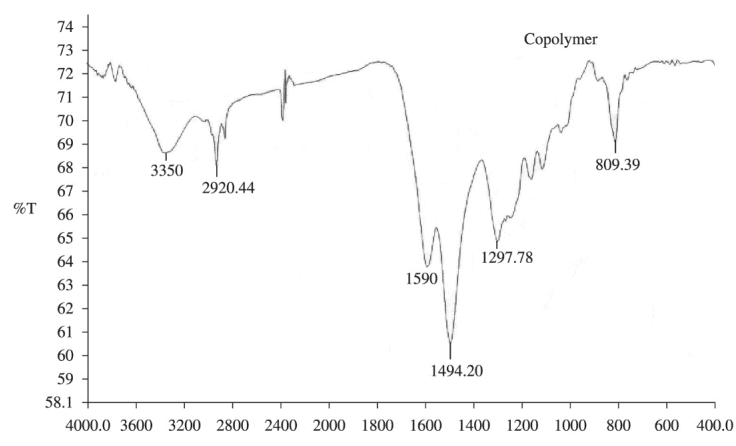

$\mathrm{cm}^{-1}$

Figure 1. FTIR spectrum of poly (aniline-co-o-toludine) copolymer.

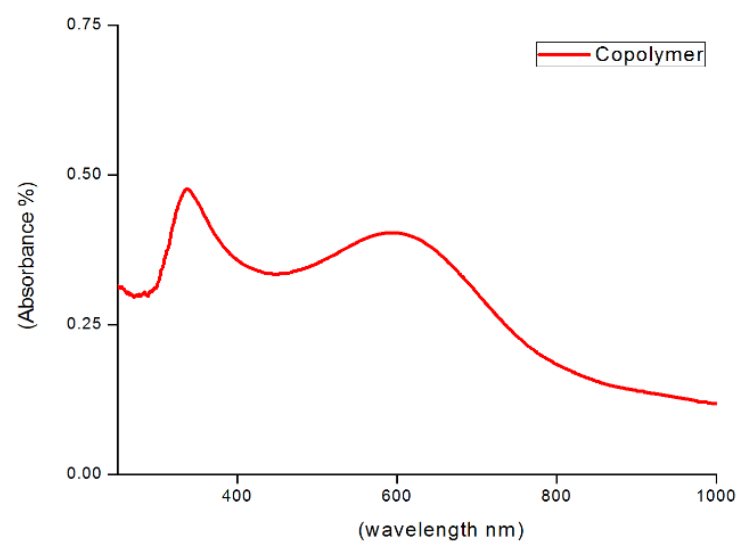

Figure 2. UV-Visible spectrum of copolymer in NMP. 
ratio of CSA is much higher than copolymer in the composites, the solvent vaporizes and excessive CSA crystallizes after spin coating and thus showing a high intensity peak at the $2 \theta$ value of $18.08^{\circ 35}$. This may be due to growth and formation of expanded chains of CSA doped copolymer and aligned orderly to one direction as clearly seen in the SEM image ${ }^{36}$. Macdiarmid et al has reported about XRD pattern of crystallized CSA doped polyaniline films and also emphasized the effect of secondary dopant $\mathrm{m}$-cresol on the expanded coil like conformation ${ }^{37}$. Figure $3 e$ shows the XRD pattern of copolymer with CSA doped and dispersed with $\mathrm{ZnO}$ nanoparticles. The three peaks at $15.39^{\circ}, 17.56^{\circ}$ and $20.59^{\circ}$ indicate the crystalline camphorsulfonic acid and the values are confirmed with JCPDS data no. 12-0907. Similar new peaks were observed with the same $2 \theta$ value of $15.44^{\circ}$ and $17.61^{\circ}$ in PPy-ZnO-CSA thin film ${ }^{38}$. After dispersing the zinc oxide nanoparticles, the ordered structure is disturbed and a hexagonal crystal structure is obtained giving rise to new peaks, which may reduce the electrostatic interaction between the copolymer and CSA. The molecular interaction between the $\mathrm{m}$-cresol phenyl ring and CSA may also decrease and thus reducing the peak intensity. The XRD pattern of pure zinc oxide nanoparticles are shown in the Figure $3 \mathrm{~d}$. The high intensity peak for $\mathrm{ZnO}$ nanoparticles is at $36^{\circ}$ and the characteristic peak at $36.32^{\circ}$ in Figure $3 \mathrm{e}$ indicating the presence of $\mathrm{ZnO}$ nanoparticles in the polymer matrix, which possesses (101) plane and it matches with JCPDS data in no.79-0208

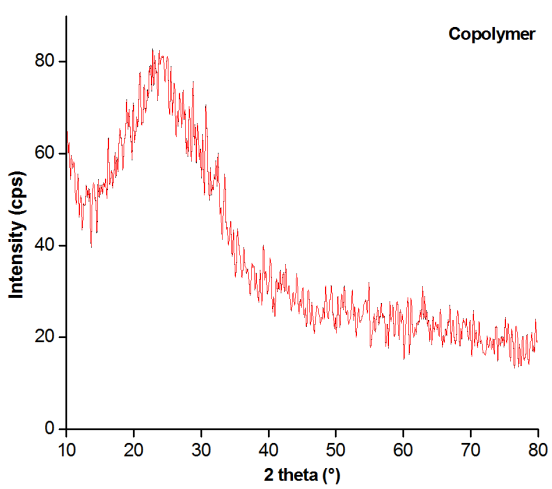

(a)

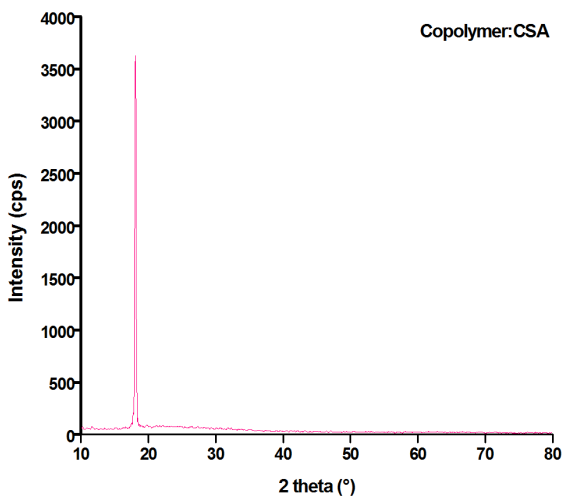

(c)

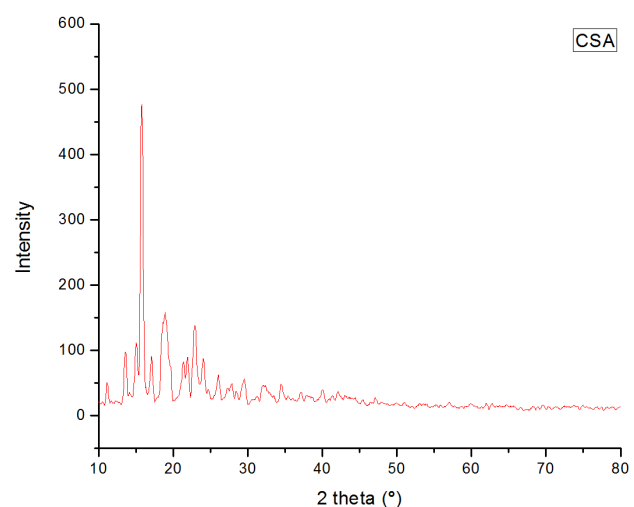

(b)

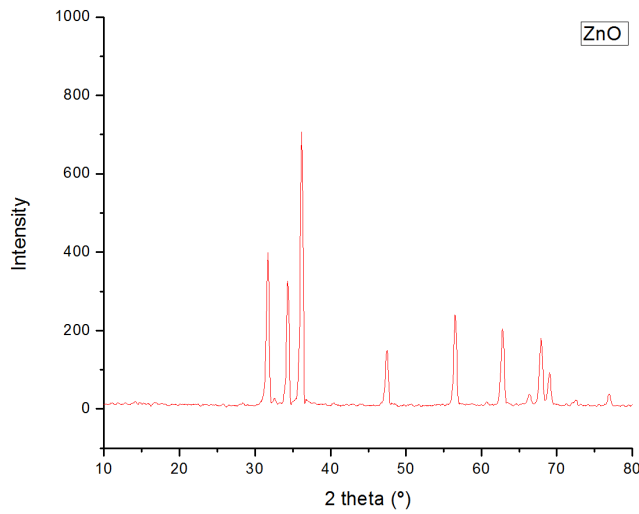

(d)

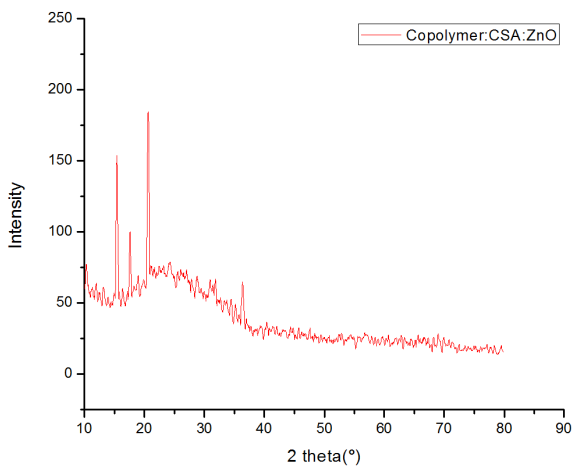

(e)

Figure 3. (a) XRD pattern of Copolymer film; (b) XRD pattern of pure CSA; (c) XRD pattern of CSA doped Copolymer; (d) XRD pattern of pure $\mathrm{ZnO}$ nanoparticles; (e) XRD pattern of CSA doped Copolymer with $\mathrm{ZnO}$ nanoparticles. 


\subsection{SEM analysis}

Figures $4 \mathrm{a}, \mathrm{b}$ and $\mathrm{c}$ show the scanning electron microscope images of the copolymer doped with CSA at different magnification. Figure 4a shows highly grown hexagonal structure in the morphology of the film. All the crystals are aligned in the same direction and Figure $4 \mathrm{~b}$ is the enlarged image shows growing crystals in the same direction. This structure may be due to the electrostatic interaction between the copolymer and CSA in presence of m-cresol and also due to the hydrogen bonding between the carbonyl group of CSA and hydroxyl groups in $\mathrm{m}$-cresol ${ }^{39}$. There also exist phenyl-phenyl interactions between the phenyl ring of $\mathrm{m}$-cresol and the neighboring copolymer ring. The van der Waals interaction between the phenyl rings of CSA and $\mathrm{m}$-cresol is described by the Lennard potential. These molecular interactions are known to cause crystalline growth of CSA and these results in the formation of hexagonal structure ${ }^{13}$.

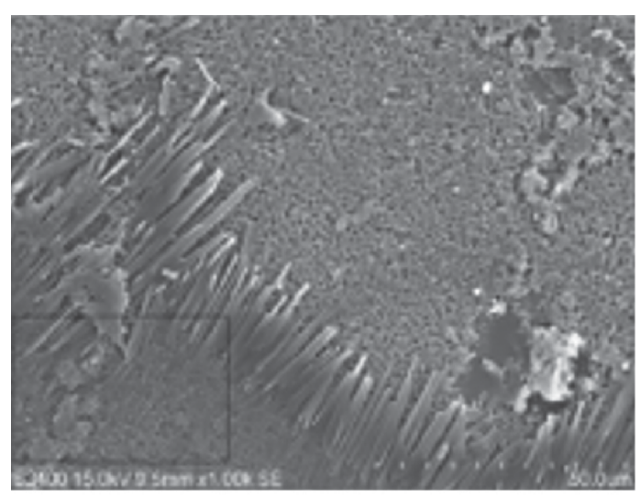

(a)

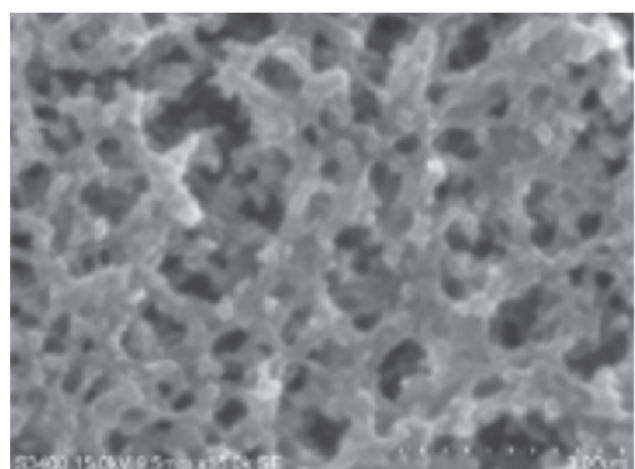

(c)

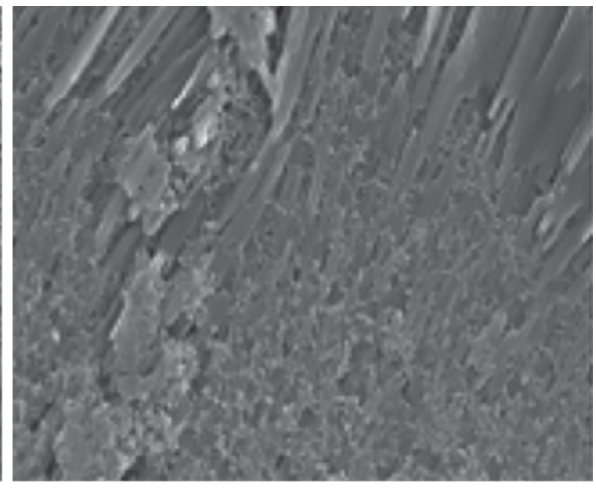

(b)

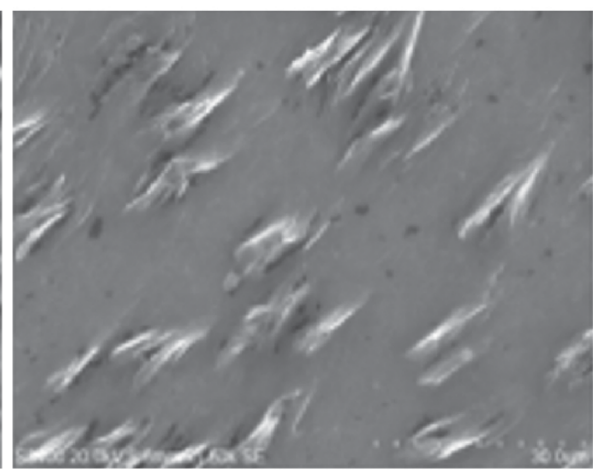

(d)

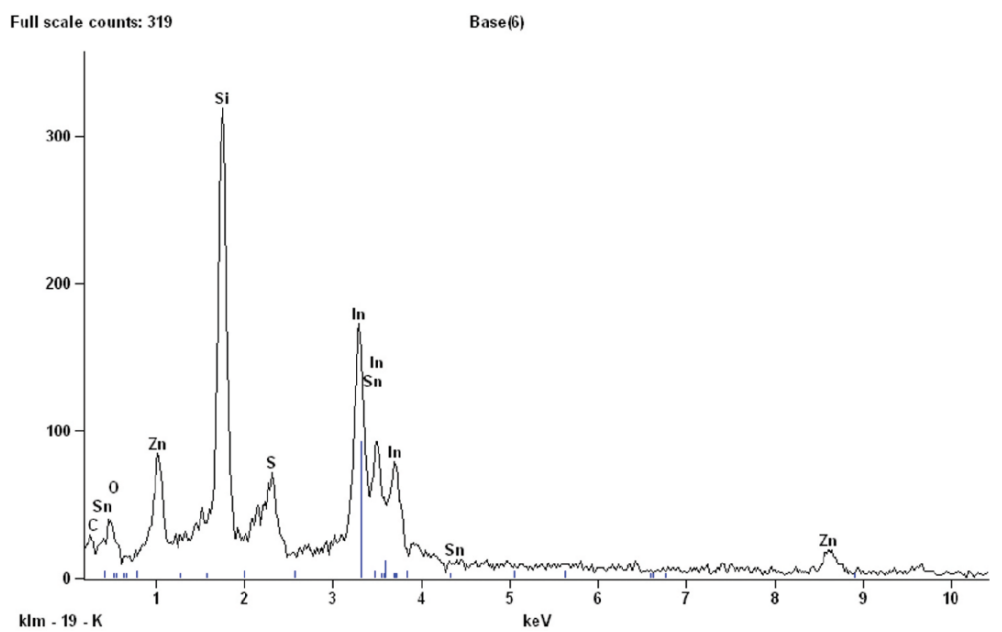

(e)

Figure 4. (a) SEM image Thin Film of CSA doped copolymer; (b) SEM image Enlarged image from Figure 4a; (c) SEM image thin film of CSA doped copolymer; (d) SEM image ZnO dispersed CSA doped copolymer; (e) EDAX spectrum of CSA doped copolymer with $\mathrm{ZnO}$ nanoparticles thin film. 


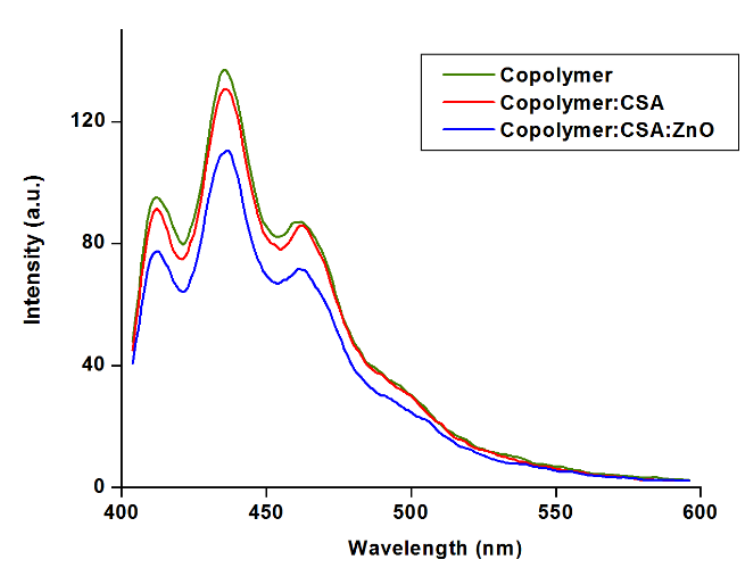

Figure 5. Photoluminescence Spectra.

Figure $4 \mathrm{c}$ shows the porous morphology of copolymer matrix and appears to be composed of mostly fibrous structure. Figure 4d shows the SEM image of the copolymer doped with CSA and dispersion of zinc oxide nanoparticles. It shows that the rods like CSA are arranged in the same direction and the corresponding EDAX result is also shown in Figure 4e. The dispersed $\mathrm{ZnO}$ nanoparticles occupy in the porous copolymer film and therefore surface becomes smooth and hexagonal crystalline rods of CSA are uniformly distributed all over the polymer film. The EDAX confirms the presence of the carbon, sulphur, oxygen and zinc.

\subsection{Photoluminescence studies}

Figure 5 shows the photoluminescence spectra of the i) copolymer, ii) CSA doped copolymer and iii). $\mathrm{ZnO}$ nanoparticles dispersed CSA doped copolymer. The photoluminescence spectra of all the samples were taken with an excitonic wavelength of $380 \mathrm{~nm}$. All the spectra show a common peak at $412 \mathrm{~nm}, 436 \mathrm{~nm}, 461 \mathrm{~nm}$ and a shoulder peak around 500 $\mathrm{nm}$. The high intensity peak at $436 \mathrm{~nm}$ is due to the polaronic band of the copolymer. When the zinc oxide nanoparticles are dispersed, there is quenching in the PL spectrum showing the charge transfer between the copolymer and nanoparticles. The PL quenching is an evidence for exciton dissociation. As the photo excitons are dissociated, the probability for recombination will be less due to the ultra fast electron

\section{References}

1. Wei Y, Focke WW, Wnek GE, Ray A and MacDiarmid AG. Synthesis and electrochemistry of alkyl ring-substituted polyanilines. Journal of Physical Chemistry. 1989; 93(1):495499. http://dx.doi.org/10.1021/j100338a095.

2. Wei Y, Hariharan R and Patel SA. Chemical and electrochemical copolymerization of aniline with alkyl ring-substituted anilines. Macromolecules. 1990; 23(3):758-764. http://dx.doi.org/10.1021/ ma00205a011.

3. Anbarasan R, Vasudevan T and Gopalan A. Chemical grafting of poly(aniline) and poly(o-toluidine) onto PET fibre - a comparative study. European Polymer Journal. 2000; 36(8):17251733. http://dx.doi.org/10.1016/S0014-3057(99)00242-6.

4. Ravi Kumar G, Vivekanandan J, Mahudeswaran A and Vijayanand PS. Synthesis and characterization of novel poly(aniline-co- transfer reaction from donor to acceptor ${ }^{40}$. The quenching in emission spectrum is more in the case of $\mathrm{ZnO}$ nanoparticles dispersed polymer because of larger surface area leading to a higher possibility of charge transfer at the copolymer/ZnO interface. Here $\mathrm{ZnO}$ semiconducting nanoparticles act as an acceptor material. Similar quenching of PL spectrum has been reported when $\mathrm{ZnO}$ nanoparticles are added to $\mathrm{MEH}-$ $\mathrm{PPV}^{41}, \mathrm{MDMO}-\mathrm{PPV}^{42,43}$ and $\mathrm{P}^{3} \mathrm{HT}^{44}$ films. This interesting quenching action in PL spectrum suggests that this copolymer composite material can be used for photovoltaic devices.

\section{Conclusions}

Poly (aniline-co-o-toluidine) copolymer has been successfully synthesized through chemical oxidation polymerization method. CSA doped Poly (aniline-co-o-toluidine) copolymer and dispersion of zinc oxide nanoparticles thin film has been successfully coated on glass substrates by spin coating technique. The synthesized copolymer is characterized by FTIR, UV, and XRD analysis. SEM study reveals the sponge like porous morphology of the copolymer composite.

$\pi-\pi^{*}$ and $n-\pi^{*}$ transition of benzonoid and quinoid groups of the copolymer are confirmed from the UV spectral studies. The FT-IR analysis confirms the chemical structure of copolymer. From the XRD pattern we can observe the crystalline nature of the CSA doped copolymer nanocomposties. Since the Poly (aniline-co-o-toluidine) copolymer is found to be highly soluble in NMP, it paves the way to have more application perspectives. The quenching in the photoluminescence spectrum indicates the charge transfer between the copolymer and the zinc oxide nanoparticles. These results strongly reveal that they are ideally suited for the manufacture of optoelectronic devices and could be used for photovoltaic application. Further extended research work in this direction will be highly useful for solar cell fabrication technology.

\section{Acknowledgements}

Authors acknowledge the Management of Bannari Amman Institute of Technology and Sri Ramakrishna Mission Vidyalaya College of Arts and Science for their immense support.

m-aminoacetophenone) copolymer nanocomposites using dodecylbenzene sulfonic aicd as a soft template. Iranian Polymer Journal. 2013; 22(12):923-929. http://dx.doi.org/10.1007/ s13726-013-0191-X.

5. Kumar D. Synthesis and characterization of poly(aniline-co-otoluidine) copolymer. Synthetic Metals. 2000; 114(3):369-372. http://dx.doi.org/10.1016/S0379-6779(00)00270-8.

6. Huang M-R, Li X-G, Yang Y-L, Wang X-S and Yan D. Oxidative copolymers of aniline with o-toluidine: their structure and thermal properties. Journal of Applied Polymer Science. 2001; 81(8):1838-1847. http://dx.doi.org/10.1002/app.1617.

7. Shreepathi S and Holze R. Benzoyl-Peroxide-Initiated inverse emulsion copolymerization of aniline and o-toluidine: effect of dodecylbenzenesulfonic acid on the physicochemical properties of the copolymers. Macromolecular Chemistry and Physics. 2007; 208(6):609-621. http://dx.doi.org/10.1002/macp.200600491. 
8. Shreepathi S and Holze R. Investigations of chemically synthesized poly(aniline-co-o-toluidine)s doped with dodecylbenzenesulfonic acid. Journal of Applied Polymer Science. 2009; 113(2):700708. http://dx.doi.org/10.1002/app.30104.

9. Benchikh A, Aitout R, Makhlouf L, Benhaddad L and Saidani B. Soluble conducting poly(aniline-co-orthotoluidine) copolymer as corrosion inhibitor for carbon steel in $3 \% \mathrm{NaCl}$ solution. Desalination. 2009; 249(2):466-474. http://dx.doi.org/10.1016/j. desal.2008.10.024.

10. Jiang J, Ai LH and Liu L-Y. Poly(aniline-co-o-toluidine)/ BaFe12O19composite: preparation and characterization. Materials Letters. 2010; 64(7):888-890. http://dx.doi.org/10.1016/j. matlet.2010.01.043.

11. Jeyakumari JL, Yelilarasi A, Sundaresan B, Dhanalakshmi V and Anbarasan R. Chemical synthesis of poly(aniline-co-o/mtoluidine)/V2O5nanocomposites and their characterizations. Synthetic Metals. 2010; 160(23-24):2605-2612. http://dx.doi. org/10.1016/j.synthmet.2010.10.011.

12. Elmansouri A, Hadik N, Outzourhit A, Lachkar A, Abouelaoualim A, Achour ME, et al. Schottky diodes and thin films based on copolymer: poly(aniline-co-toluidine). Active and Passive Electronic Components.2009; 2009:378086.

13. Verma D and Dutta V. Novel microstructure in spin coated polyaniline thin films. Journal of Physics: Condensed Matter. 2007; 19(18):186212.

14. Han YK, Chang MY, Ho KS, Hsieh TH, Tsai JL and Huang PC. Electrochemically deposited nano polyaniline films as hole transporting layers in organic solar cells. Solar Energy Materials and Solar Cells. 2014; 128:198-203. http://dx.doi. org/10.1016/j.solmat.2014.04.031.

15. Bejbouji H, Vignau L, Miane JL, Dang MT, Oualim EM, Harmouchi M, et al. Polyaniline as a hole injection layer on organic photovoltaic cells. Solar Energy Materials and Solar Cells. 2010; 94(2):176-181. http://dx.doi.org/10.1016/j. solmat.2009.08.018.

16. Wang W, Schiff E and Wang Q.Amorphous silicon/polyaniline heterojunction solar cells: fermi levels and open circuit voltages. Journal of Non-Crystalline Solids. 2008; 354(19-25):2862-2865

17. Baxter JB and Aydil ES, Nanowire-based dye-sensitized solar cells. Applied Physics Letters.2005;86:53114.

18. Huang MH, Mao S, Feick H, Yan HQ, Wu Y, Kind H, et al. Room temperature ultraviolet nanowire nanolasers. Science. 2001; 292:1897-1899.

19. Song J, Zhou J and Wang ZL. Piezoelectric and semiconducting coupled power generating process of a single $\mathrm{ZnO}$ belt/wire. A technology for harvesting electricity from the environment. Nano Letters. 2006; 6(8):1656-1662. http://dx.doi.org/10.1021/ nl060820v. PMid:16895352

20. Wang ZL. Functional oxide nanobelts: materials, properties and potential applications in nanosystems and biotechnology. Annual Review of Physical Chemistry. 2004; 55(1):159-196. http://dx.doi.org/10.1146/annurev.physchem.55.091602.094416. PMid:15117251

21. Sawai J, Igarashi H, Hashimoto A, Kokugan T and Shimizu M. Effect of ceramic powder slurry on spores of bacillus subtilis. Journal of Chemical Engineering of Japan. 1995; 28(5):556561. http://dx.doi.org/10.1252/jcej.28.556.

22. Gonzalez-Valls I and Lira-CantuM. Vertically aligned nanostructures of $\mathrm{ZnO}$ for excitonic solar cells : a review energy.Environmental Sciences. 2009; 2:19-34.

23. SulimanAE, Tang Y and Xu L. Preparation of ZnO nanoparticles and nanosheets and their application to dye-sensitized solar cells.
Solar Energy Materials and Solar Cells. 2007; 91(18):16581662. http://dx.doi.org/10.1016/j.solmat.2007.05.014.

24. Tang E, Cheng G and Ma X. Preparation of nano-ZnO/PMMA composite particles via grafting of the copolymer onto the surface of zinc oxide nanoparticles. Powder Technology. 2006; 161(3):209-214. http://dx.doi.org/10.1016/j.powtec.2005.10.007.

25. Kaushik A, Kumar J, Tiwari MK, Khan R, Malhotra BD, Gupta $\mathrm{V}$, et al. Fabrication and characterization of polyaniline-znO hybrid nanocomposite thin films. Journal of Nanoscience and Nanotechnology. 2008; 8(4):1757-1761. http://dx.doi. org/10.1166/jnn.2008.006. PMid:18572575

26. Wang YZ, Joo J, Hsu CH and Epstein AJ. Charge transport of camphor sulfonic acid-doped polyaniline and poly(o-toluidine) fibers: role of processing. Synthetic Metals. 1995; 68(3):207211. http://dx.doi.org/10.1016/0379-6779(94)02304-H.

27. Matveeva ES, Parkhutik VP, Calleja RD and HernandezFuentes I. Variation of a.c. electrical properties of emeraldine base of polyaniline during its drying from suspension in m-cresol. Synthetic Metals. 1996; 79(2):159-163. http://dx.doi. org/10.1016/0379-6779(96)80185-8.

28. Silva JEP, Torresi SIC, Temperini MLA, Goncalves D and Oliveira ON Jr. A comparative study of m-cresol treated polyaniline and Langmuir Blodgett films. Synthetic Metals. 1999; 101(1-3):691. http://dx.doi.org/10.1016/S0379-6779(98)00801-7.

29. Cocher M, Corraze B, Quillard S, Buisson JP, Lefrant S and Louarn G. Electronic and vibrational changes induced by different acidic vapors in polyaniline. Synthetic Metals. 1997; 84(13):757-758. http://dx.doi.org/10.1016/S0379-6779(96)04132-X.

30. González I, Vecino M, Munoz E, Santamarı A and Pomposo A. Electrically conducting gels formed from Polyaniline/ Ethylcellulose/m-Cresol ternary solutions. Macromolecular Chemistry. 2004; 205(10):1379-1384. http://dx.doi.org/10.1002/ macp. 200400109.

31. Lee K, Cho S, Park SH, Heeger AJ, Lee CW and Lee SH. Metallic transport in polyaniline. Nature. 2006; 441(7089):6568. http://dx.doi.org/10.1038/nature04705. PMid:16672965

32. Garai A and Nandi AK. Rheology of ( \pm )-camphor-10-sulfonic acid doped polyaniline-m-cresol conducting gel nanocomposites. Journal of Polymer Science. Part B, Polymer Physics. 2008; 46(1):28-40. http://dx.doi.org/10.1002/polb.21339.

33. Lee K-H, Park BJ, Song DH, Chin I-J and Choi HJ. The role of acidic $\mathrm{m}$-cresol in polyaniline doped by camphorsulfonic acid. Polymer. 2009; 50(18):4372-4377. http://dx.doi.org/10.1016/j. polymer.2009.07.009.

34. Xin LY, Zhang X-G, Zhang G-Q and Shen C-M. Synthesis and characterization of aniline and o-toluidine conducting copolymer microtubes with the template-synthesis method. Journal of Applied Polymer Science. 2005; 96(5): 1539-1543. http://dx.doi.org/10.1002/app.21548.

35. He C, Tan Y and Li Y. Conducting polyaniline nanofiber networks prepared by the doping induction of camphor sulfonic acid. Journal of Applied Polymer Science. 2003; 87(9):1537-1540. http://dx.doi.org/10.1002/app.11599.

36. Yan H, Ohta T and Toshima N. Stretched Polyaniline films doped by $( \pm)$-10- camphorsulfonic acid: Anisotropy and improvement of thermoelectric properties. Macromolecular Materials and Engineering. 2001; 286(3):139-142. http:// dx.doi.org/10.1002/1439-2054(20010301)286:3<139::AIDMAME139>3.0.CO;2-F.

37. MacDiarmid AG and Epstein AJ. The concept of secondary doping as applied to polyaniline. Synthetic Metals. 1994; 65(23):103-116. http://dx.doi.org/10.1016/0379-6779(94)90171-6. 
38 Chougle MA, Khuspe GD, Sen S and Patil VB. Polypyrrole-ZnO nanohybrids: effect of CSA doping on structure, morphology and optoelectronic properties. Applied Nanoscience. 2013; 3(5):423-429.

39. Ikkala OT, Pietila L-O, Ahjopalo L, Osterholm H and Passiniemi PJ. On the molecular recognition and associations between electrically conducting polyaniline and solvents. The Journal of Chemical Physics. 1995; 103(22):9855-9863. http://dx.doi. org/10.1063/1.469952.

40. Middya S, Layek A, Dey A and Ray PP. Morphological impact of $\mathrm{ZnO}$ nanoparticle on MEHPPV: $\mathrm{ZnO}$ based hybrid solar cell. Journal of Materials Science Materials in Electronics. 2013; 24(11):4621-4629. http://dx.doi.org/10.1007/s10854-013-14532 .

41. Ton-That C, Phillips MR and Nguyen T-P. Blue shift in the luminescence spectra of MEH-PPV films containing $\mathrm{ZnO}$ nanoparticles. Journal of Luminescence. 2008; 128(12):20312034. http://dx.doi.org/10.1016/j.jlumin.2008.07.004.

42. Beek WJ, Wienk MM, Kemerink M, Yang X and Janssen RAJ. Hybrid zinc oxide conjugated polymer bulk heterojunction solar cells. The Journal of Physical Chemistry B. 2005; 109(19):95059516. http://dx.doi.org/10.1021/jp050745x. PMid:16852143

43. Beek WJE, Slooff LH, Wienk MM, Kroon JM and Janssen RAJ. Hybrid solar cells using a Zinc oxide precursor and a conjugated polymer. Advanced Functional Materials. 2005; 15(10):1703-1707. http://dx.doi.org/10.1002/adfm.200500201.

44. Zhang L, Li F, Chen Y, Peng X and Zhou W. Stably dispersible $\mathrm{P} 3 \mathrm{HT} / \mathrm{ZnO}$ nanocomposites with tunable luminescence by in-situ hydrolysis and copolymerization of zinc methacrylate. Journal of Luminescence. 2010; 130(12):2332-2338. http:// dx.doi.org/10.1016/j.jlumin.2010.07.014. 